\title{
Exploration of Psychosocial Risk and the Handling of Unsafe Acts and Misconducts in the Workplace
}

\author{
Jan Visagie \\ Director School of Human Resource Management, North-West University, South Africa \\ Email: jan.visagie@nwu.ac.za \\ Jacquelene Swanepoel
}

School of Human Resource Management, Masters Student, North-West University, South Africa

Wilfred I. Ukpere

Department of Industrial Psychology and People Management, Faculty Of Management, University of Johannesburg

\section{Doi:10.5901/mjss.2014.v5n20p997}

\section{Abstract}

The aim of this article was to investigate the psychosocial risk environment influencing employee behaviour, and subsequently the trust relationship between employer and employee. The unique nature and commonness of negative acts, such as unsafe behaviour, human errors, poor performance and negligence (also referred to as unsafe practices) are explored in this article. Pertinent literatures were reviewed on the nature of negative acts or unsafe behaviour. The findings of this study were used to draw comparisons between unsafe behaviour/misconduct and accidents in the workplace and finally recommendations were made on how the problem can be addressed from a labour relations perspective. The results indicate that a relationship between unsafe practice/misconduct and occupational injuries and accidents exist, owing to system flaws, human error or psychosocial risk.

Keywords: Occupational risks, Unsafe practice, Misconduct, Ergonomics, Management commitment, leadership, labour relations

\section{Introduction}

In a scenario of production urgency that was examined at a large manufacturing plant in South Africa, where this study was conducted, two operators were found in violation of the 'lock out' procedure while working on moving machinery. The operators were focused on their set tasks, when production quality was influenced by a technical fault on the machine. The fault was set in the basement/pit of the machine near large moving rollers. The operators decided to investigate and to rectify the mistake at the source of the danger zone to find the error, where access is strictly forbidden. A year prior to this incident, one employee suffered a severe injury at the same machine and work area. The employee had been permanently disabled after he lost the fingers $(2,3,4$, and 5$)$ on both of his hands. Despite being aware of this serious injury, the two operators deliberately violated the safety rules and entered the forbidden danger zone, without applying the emergency stop. The operators knowingly placed their own lives in danger.

The operators were duly aware of the rule and a notification sign was visible at the entrance of the forbidden area, stating that access is only allowed after the machine had been 'locked out'. After the incident, the two operators were charged with misconduct and were informed to attend a disciplinary hearing. The manufacturing company consistently applies a zero tolerance policy for safety violations and safety misconduct. This action was viewed as a serious offence, which the employer could not allow (CCMA Case Number: GATW6161/13).

This scenario, along with other examples, will be used throughout this article to understand the reason for discrepancies, involving individuals' attitudes and behaviour. This article will further consider cases, as stated above, in context of a high risk work environment, and the influence thereof on the trust relationship between employer and employee. The 'work environment' referred to in this article is considered in its largest sense and includes the social - as well as the physical environment of the organisation and the relationship between an organisation and the environment in which it operates (Grandjean, 1988; Robbins, et al., 2007). It is argued that even if the system has been designed to take account of all the ergonomic principles, statistics shows that accidents still occur when a human operator is involved 
(Oborne, 1985), because accidents are often attributed to human error and the nature of an operator's behaviour (Oborne, 1985; Bridger, 2003). However, behaviours are never random and do not occur without some thought process preceding it (Kruger and Wyngaard, 2009). To understand the reasons behind unwanted behaviour, the 'second story' or 'full account' namely the thought patterns and the context within which they occur, should be considered (Kruger and Wyngaard, 2009). Therefore, the working interface of organisational factors that give life to these individual or group behaviours must be taken into consideration.

There is a general tendency to associate poor system performance with poor human performance. Yet, detailed analyses of accidents and incidents of 'near misses' reveal that human error is almost never the sole cause (Bailey, 1982). It has been argued that workplace accidents are frequently the result of human error, which in turn is the unfortunate outcome of flawed systems of work (Health and Safety Authority, 2004). Real systems are multi-layered and hierarchical and errors can only lead to accidents if they have consequences at other levels (Bridger, 2003). It is further argued that accidents do not always follow automatically from risk-taking behaviour. As a result of knowing the system, people learn to make informed guesses about when they can 'get away with' taking a risk, both in the workplace and in other spheres of life (HSA, 2004). Kruger and Wyngaard (2009) refers to a thought process that calculates potential effects by an 'if-then' formula, including previous experience and prioritising of desired outcomes or goals.

Therefore, in considering the behaviour of the operators in the above analysis, it may be surmised people usually act in a certain way based on the consequence they expect from their actions. Geller (2005:542) put it thus: "People follow through with the particular behaviour activated to the extent they expect doing so will provide them a pleasant consequence or enable them to avoid an unpleasant consequence" Finally, in order to fully comprehend the complex interactive phenomenon between the man-machine-environment and how the psychosocial risk environment affects individual and group behaviour, organisational behaviour as a whole must be examined. Organisational behaviour applies the knowledge gained about individuals, groups and the effect of structure on behaviour in order to make organisations to function more effectively (Robbins, et al., 2007).

\section{Problem Statement}

The problem derived from the above introduction is that the psychosocial risk environment will either provoke desirable or undesirable behaviour from the individual employee, subsequently influencing the trust relationship between employer and employee and the organisation as a whole.

\subsection{Research questions}

- What mindset could have triggered unwanted behaviors within a psychosocial work environment?

- What series of actions were considered by employees before they made the decision to ignore company regulations?

- What are the effect of unwanted behaviours on the labour relationship between employer and employee in the workplace?

- Is there any interactive relationship between the three determinants of behaviour in organisations, namely individual, groups and structures?

\subsection{Research objectives}

The objectives of this paper are:

- To examine the dynamics of the psychosocial environment and the risks that the human behaviour can introduce into a 'safe' situation, that might lead to an 'unsafe' situation.

- To investigate the reasons for the tolerance of safety and organisational culture violations in the work environment,

- To understand the effect of unwanted behaviours on the labour relationship between employer and employee in the workplace, and

- To investigated the interactive relationship between the three determinants of behaviour in organisations, namely individual, groups and structures. 


\section{Literature Review}

It is believed that undesirable behaviour and interaction with the work environment are the cause of $80-96 \%$ of workplace injuries. In other words, accidents only occur when an employee interacts with the condition in an unsafe manner (Strydom, 2009). Behavioural Based Safety (BBS) looks for external factors to understand and improve behaviour. According to Geller (2005), behaviour is influenced by factors in both the internal and external environments. Environmental conditions that influence behaviour include inadequate management systems or managers' behaviours that promote risk behaviours (Geller, 2005). BBS focuses on what people do, and then analyses why they do it (Geller, 2005). Ajzen (1991) developed a model focusing on intentions as the key link between attitudes and planned behaviour. The theory of planned behaviour includes three (3) interacting determinants of one's intention to exhibit a specific behaviour (Kreitner \& Kinicki, 2008). These three determinants include one's attitude towards certain behaviour, the subjected norm and perceived behavioural control. The unique interaction between the three determinants will be explained in more detail below with reference to an incident that occurred at the manufacturing plant where this research was conducted.

Figure 1: Ajzen's Theory of Planned Behaviour (Model 1)

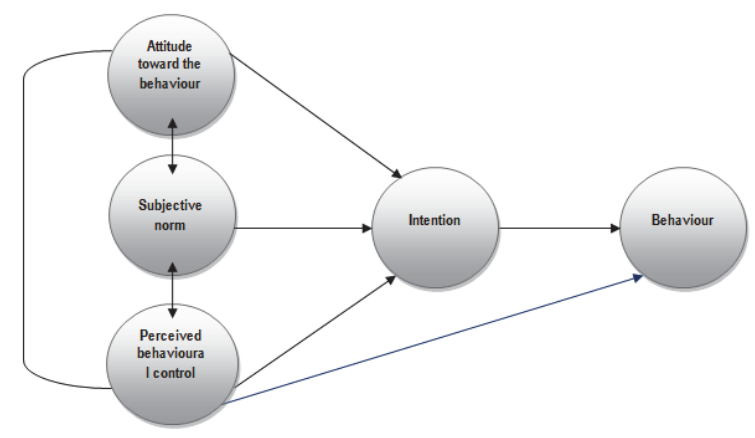

Source: Ajzen (1991:182)

The following case study will be used to explain the above model above: An employee, who was employed as an operator at a fast moving manufacturing machine, has a favourable attitude towards ignoring the safety rule to switch off the machine to rectify errors on the material produced by the machine. By doing this, the employee is required to move her hand into a danger zone of the machine. Her perceived subjective norm is favourable because she sees her coworkers taking shortcuts to rectify errors on the machine in the same manor. It is also observed that this behaviour has previously been either allowed by management, or management have never been aware of this unwarranted behaviour (EAR No: 06/14/01). Hence, in terms of the perceived behaviour control, she is completely in charge of acting on her intention to take the shortcut, and subsequently ignores the safety rule. The employee entered the danger zone, as she and her co-workers have done many times before. However, without expecting it, an accident occurred and the employee suffered an injury (lacerations to the left hand) and subsequently lost some days from work. Therefore, a person's intention to engage in a given behaviour is a strong predictor of that behaviour. Kreitner and Kinicki (2008) explain this further and stated that the quickest and possibly most accurate way of determining whether an individual will quit his or her job is to have an objective third party asked if he or she intends to quit. In the same sense, and with reference to the above incident, in order to determine whether an individual will show undesirable/unsafe behaviour, it is necessary to determine whether the said bad behaviours are accepted as the norm among all other employees (for example to take shortcuts at work to save production time). Therefore, it is suggested that risk taking behaviour can be predicted by using the theory of planned behaviour model.

The theory further has important managerial implications. Kreitner and Kinicki (2008) explain that this model allows the realisation that behaviour is modified through intentions, which are influenced by the three determinants in the model. Therefore, if the model is applied correctly, it can influence behavioural change by doing or saying things that affect the three determinants of employees' intentions to exhibit a specific behaviour: attitude toward the behaviour; subjective norms and perceived behavioural control. Kreitner and Kinicki (2008) elaborate that this is accomplished by modifying the 
specific beliefs that foster each of these determinants. For example, behavioural beliefs, normative beliefs and control beliefs directly affect attitude toward the behaviour, subjective norms and perceived behavioural control. Therefore, employee beliefs can be influenced through the information management provides on a day-to-day basis, organisational culture values, role models and rewards that are targeted to reinforce certain beliefs (Kreitner \& Kinicki, 2008).

\subsection{Psychosocial risk}

Workplace psychosocial factors are non-physical aspects of the workplace that are developed by the culture, policies, expectations and social attitude of the organisation (Canadian Centre for Occupational Health \& Safety, 2012). Psychosocial factors are associated with the way individuals interact with the demands of their job and their work environment (Green \& Taylor, 2008). It is important to understand that the term 'psychosocial' is different from 'psychological', which refers more narrowly to thought processes and behaviour of individuals (Burton, Kendall, Pearce, Birrell \& Bainbridge, 2008). Psychosocial risks are organisational factors that affect the psychological safety and health of employees (Gilbert, 2010). Psychosocial factors include the way the work is carried out (deadlines, workload, work methods) and the context within which work occurs, including relationships and interactions with managers and supervisors, colleagues and co-workers and clients/customers (Guarding Minds at Work, 2012). Thirteen psychosocial factors have been identified and summarised from previous research by Samra, Gilbert, Shain and Bilsker (2012). The factors (PSR-13) are interrelated and therefore influence one another. The thirteen factors (PSR-13) assessed by Samra et al. (2012) correlates with an earlier study done by Green and Taylor (2008), although with slight variances. From Green and Taylor (2008) perspective, social support is the amount of input that workers perceived they receive from coworkers. However, Samra et al. (2012) elaborates on psychological support and a work environment where co-workers and supervisors are supportive of employees' psychological and mental concerns, and respond appropriately as needed. While Green and Taylor (2008) mention a sense of community (the degree to which workers feel that they are part of a community), Samra et al. (2012) refer to organisational culture and a work environment characterised by trust, honesty and fairness.

In addition, both studies highlight the quality of leadership, clear leadership and expectations, including civility and respect. Other psychosocial risks identified by the authors include work demands and mental loads; subsequently work stress, management feedback, including recognition and reward, involvement and influence, job control, psychological protection and protection of physical safety (for more detail see Green \& Taylor, 2008:2; Samra, et al., 2012:2). Therefore, psychosocial risks are constituted by organisational factors, such as lack of supportive relationships at work, job insecurity or company culture (Houtman, 2008). Exposure to psychosocial risk factors at work may result in a state of work-related stress (psychological), in which one often feels tense, concerned, less vigilant and less efficient in performing tasks (Houtman, 2008; Rick, Briner, Daniels, Perryman \& Guppy, 2001), leading to increased absenteeism, withdrawal behaviour, conflict, strain (fatigue, burnout, anxiety), turnover, loss of production, and greater risk of accidents, incidents and injuries (Canadian Centre for Occupational Health \& Safety, 2012). Work-related stress depends on individual perceptions of their work environment, dependant on resources available in the workplace and in the organisation (for example, the support of co-workers and supervisors). These psychosocial risks can have negative consequences on the organisation as a whole, including negative health outcomes, increased risk for accidents and impaired performance (Houtman, 2008; Cassitto, Fattorini, Gilioli \& Rengo, as cited by WHO, 2013). This will in turn also influence the labour relationship in terms of employers' expectations versus employees' abilities to perform. It is undeniable that psychosocial risks do not only play a significant role in organisational effectiveness, they further have an important impact on human resource management, and more specifically on labour relations.

\subsection{Occupational stress}

As mentioned earlier, occupational stress is often the result of exposure to psychosocial risk. Pressure at the workplace is unavoidable due to the demands of the industrial work environment (Leka, Griffiths \& Cox, 2005). When pressure becomes excessive or otherwise unmanageable it leads to stress. Therefore, stress results from a mismatch between the demands and pressures on the person, on the one hand and their knowledge and abilities on the other. It challenges their ability to cope with work (Leka, et al., 2005). This includes not only situations where the pressures of work exceed the worker's ability to cope but also where the worker's knowledge and abilities are not sufficiently utilised (boredom). Furthermore, Ritchie and Martin (1999) explain that someone with a high score on the need for good working conditions would suffer from stress if they worked in draughty, dingy work environment with a lot of noisy machinery. Poor work organisation, with reference to job design and work systems, can cause work stress (Leka, et al., 2005). Most of the 
causes of stress are concerned with the way work is designed and the way in which organisations are managed. Leka et al., (2005) refer to these aspects as "stress related hazards". Stress-related hazards include, but are not limited to, the following aspects, summarised in Table 1 below:

Table 1: Stress-related hazards (psychosocial risk factors)

\begin{tabular}{|c|c|l|}
\hline 1. & Job Content & $\begin{array}{l}\text { Monotonous, under-stimulating, meaningless tasks; } \\
\text { Lack of variety; Unpleasant task; Aversive task. }\end{array}$ \\
\hline 2. & Workload and Work pace & $\begin{array}{l}\text { Having too much or too little to do; } \\
\text { Working under time pressure. }\end{array}$ \\
\hline 3. & Working Hours & $\begin{array}{l}\text { Strict and inflexible working schedules; } \\
\text { Long and unsocial hours; } \\
\text { Unpredictable working hours; } \\
\text { Badly designed shift systems. }\end{array}$ \\
\hline 4. & Participation and control & $\begin{array}{l}\text { Lack of participation in decision making; } \\
\text { Lack of control over the work environment. }\end{array}$ \\
\hline 5. & Interpersonal Relationships & $\begin{array}{l}\text { Inadequate, inconsiderate or unsupportive supervision; } \\
\text { Poor relationships with co-workers; } \\
\text { Harassment and violence; } \\
\text { Isolated or solitary work; } \\
\text { No agreed procedures for dealing with problems or complaints }\end{array}$ \\
\hline 6. & Home-work interface & Conflicting demands of work and home. \\
\hline
\end{tabular}

Source: Leka, et al., (2005:6)

The experience of work stress, caused by the exposure to psychosocial risks and -hazard factors (as summarised above) can cause unusual and dysfunctional behaviour at work and contribute to poor physical and mental health (Leka, et al., 2005). According to Geller (2005) people do what they do based on factors in both their external and internal worlds. In relation with the above, psychosocial risk assessment techniques that identify environmental conditions that influence behaviour, is another cost effective manner to change behaviour, where behaviour change is needed (Geller, 2005). It is widely accepted that effective risk controls depend in part on the behaviour of individuals at all levels within an organisation (Fleming \& Lardner, 2002). Good systems, procedures and engineering controls on their own are not enough - it is how well an organisation 'lives' its systems that matters (Fleming \& Lardner, 2002). This can include identifying inadequate management systems, or management behaviours that promote or inadvertently encourage at-risk work practices as stated above (Geller, 2005; Houtman, 2008; Leka \& Cox, 2008). The above summary brings us closer to the answer of the question asked in the introduction of this article: Why did the employees act in an unacceptable/undesirable manner, in terms of the known safety rules. It is now clearer that particular behaviour is activated by environmental (physical and psychological) influences, driven by outcomes and consequences. This concept will be further considered and discussed below.

\subsection{Drivers of behaviour}

The core element to promote health and safety behaviour is the $A B C$ model of behaviour, referring to Antecedents $(A)$, Behaviour (B) and Consequence (C) (Daniels, 2000; Geller, 2005).

Antecedents refer to a casual event (trigger) preceding the behaviour, including rules and procedures, suitable tools and equipment, information, signs, skills and knowledge, training and understanding of other people's expectations, etc. (Fleming \& Lardner, 2002). Although antecedents are necessary to trigger desired behaviour, their presence does not guarantee that behaviour will occur (Fleming \& Lardner, 2002), in that consequence drives behaviour. Consequence is defined as "the outcome of the behaviour for the individual that influences the likelihood that the behaviour will be repeated"; therefore, the frequency of behaviour can be increased or decreased by altering the consequence following the behaviour (Fleming \& Lardner, 2002:5). 
Table 2: Examples of the different types of consequence

\begin{tabular}{|l|l|l|}
\hline Positive reinforcement & Negative reinforcement & Punishment \\
\hline Positive feedback about achievement. & Avoidance of peer disapproval & Removal of benefits \\
\hline Recognition from management. & Avoidance of pain & Disciplinary action \\
\hline Praise from colleagues & Avoidance of the loss of financial reward & Physical pain or injury \\
\hline Prizes & Avoidance of financial penalty/fine & Feeling guilty \\
\hline
\end{tabular}

Source: Fleming \& Lardner (2002:5)

Reinforcements, as stipulated above, are important in terms managing (driving) behaviours at work. Leaders are challenged to cultivate a work culture that facilitates responsibility or self-accountability for safety (Geller, 2005). Positive reinforcements allow discretionary efforts that involve doing more than the minimum required and maximising safe performance because a person wants to, rather than has to (Fleming \& Lardner, 2002). Negative reinforcement produces just enough of behaviour to avoid something unpleasant, while positive reinforcement produces more behaviour than required (Daniels, 2000. This is further important to consider when dealing with misconduct in the workplace and punishing unwanted behaviours (labour relations management). Geller (2005) differentiates between accountability and self-accountability or responsibility (p. 557): "When people are held accountable, they are asked to reach a certain objective or goal, often within a designated time period. However, they might not feel responsible to meet the deadline, or might feel responsible enough to complete the assignment, but nothing more. In this case, accountability is the same as responsibility. When people extend their responsibility beyond accountability they do more of what is required. They go beyond the call of duty defined by a particular accountability system. This is often essential when it comes to occupational risk management - to improve safety beyond the current performance plateaus. Workers need to extend their responsibility for safety beyond that for which they are held accountable."

\subsection{Safety culture}

Based on the above discussion on accountability and self-accountability or responsibility, the following assumption could be made that safe behaviour is driven by consequence, which in turn, relies on the existence of a safety culture, cultivated by the leaders of the organisation. A safety culture is directly dependent on the attitude of employees towards safety (Attock Refinery Limited, 2013). The product of individual and group values, attitudes, perceptions, competencies, and patterns of behaviour that determine the commitment to, and the style and proficiency of an organisation's health and safety management (U.K Health and Safety Commission, as cited by ARL, 2013). Regardless of safety management systems, policies and procedures, incident data shows that the majority of incidents and accidents in the workplace are a result of employees' attitude, perceptions and patterns of behaviour, such as to take shortcuts and intuitive-based decisions, bypassing Standard Operating Procedures (SOP's), rules and regulations (ARL, 2013). This directly correlates with the example given in the introduction of this paper and is commonly found in the majority of incident investigation reports at the researched manufacturing plant, where this empirical study was conducted.

Organisational culture refers to a system of shared meaning held by members, distinguishing the organisation from other organisations (Schein, 1985). This system of shared meaning is a set of key characteristics that the organisation values (Robbins, Odendaal \& Roodt, 2007). Organisational culture represents a common perception held by the organisation's members and is concerned with how employees perceive the characteristics of an organisation's culture, not with whether or not they like them (Robbins et al., 2007). Therefore, it is further argued and believed that individuals with different backgrounds or at different levels in the organisation will tend to describe the organisation's culture in similar terms (Meyerson \& Martin, 1987). Safety culture is: "that assembly of characteristics and attitudes in organisations and individuals, which establishes that as an overriding priority, safety issues receive the attention warranted by their significance" (Reason, 1997:194). According to this definition not all organisations have a safety culture; only organisations for which safety is an overriding priority have safety culture. Therefore, a safety culture is something that is strived towards, but rarely attained, in that a safety culture of an organisation may vary in its effectiveness (Hopkins, 2002). According to Hale (2000), "cultural influence on safety is a more appropriate term in that it suggests that where a culture exhibits a strong emphasis on safety, a culture of safety (safety culture) exists". Attitudes are a key element of a safety culture, and an organisation can improve its safety culture and in turn its safety records, by modifying the attitudes of both management and employees towards safety (HSA, 2004). 


\subsection{Management and control}

As mentioned above, the effectiveness of a safety culture is dependent on the overall organisational behavior. The manmachine-environment concept is still valid and should not be forgotten (Oborne, 1985). It is believed that the majority of incidents are caused by unsafe behaviour, however, it has now been established that behaviour is never random and that it is very much influenced by the organisational structure as well as culture, group and individual perceptions and attitudes towards safety, driven by consequence, as cultivated by management. It is argued that workplace accidents caused by human error are frequently the unfortunate result of flawed systems of work (Health and Safety Authority, 2004). Major accidents can frequently be traced to failures in safety management systems (Keltz, 1994, as cited by Hopkins, 2002). This reinforces the need to review the Swiss Cheese Model. The 'Swiss Cheese' Model, designed by Reason (1997), uses an analogy in which an initial fault gets into the system, progressing along an 'accident trajectory' that depends on a weakness at the next level of system organisation (Hopkins, 2002; Bridger, 2003). If all the weaknesses, at all levels, coincide, like slices of Swiss cheese momentarily aligned so that it can be seen through the holes, an accident trajectory exists and an accident will occur (Bridger, 2003).

Figure 2: Swiss Cheese model of accidents (Model 2)

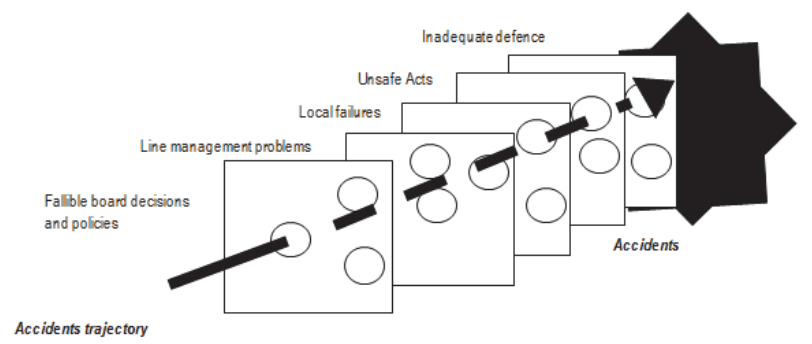

Source: Bridger (2003:467)

The Swiss Cheese Model (Model 2) illustrates that high technology systems will frequently suffer from weaknesses and failures in its defensive layers. According to Reason (2000, as cited by BMJ), high technology systems have many defensive layers: some are engineered (alarms, physical barriers, automatic shutdowns, etc.), others rely on people (control room operators, etc.) and yet others rely on procedures and administrative controls. In an ideal world, each defensive layer would be intact. However, in reality they are more like slices of Swiss cheese (Model 2), having many holes, which are continually opening, shutting and shifting their location (Reason, 2000, as cited by BMJ). According to the Model (2), a trajectory of accident opportunities is permitted when the holes in many layers momentarily line up bringing hazards into damaging contact with victims (Reason, 2000). Furthermore, the holes in defences arise for two reasons: active failures and latent conditions. To explain how nearly all adverse events involve a combination of these two sets of factors (as cited by BMJ, 2000), a practical example of a real incident that occurred on 18 May 2013 at a plant of the researched manufacturing group will be used. The operator was performing his normal duties on the day of the incident when he managed to get his neck caught between a 'can pusher' and a frame of a pigment supply unit (See pictures 1-3 below). The same question asked in the Introduction is why did this brutal accident occur? According to the model, as stated above, the answer is the combination of active failures and latent conditions.

Active failures are the unsafe acts committed by people who are in direct contact with the system, and take a variety of forms - slips, lapses, fumbles, mistakes and procedural violations (Reason, 1990). Latent conditions are the inevitable 'resident pathogens' within the system and arise from decisions made by designers, builders, procedure writers, and top-level management (Reason, 2000). Latent conditions have two kinds of adverse effects. Firstly, they can translate into error provoking conditions within the local workplace (e.g. time pressure, understaffing, inadequate equipment, fatigue, and inexperience), and secondly, they can create long-lasting holes or weaknesses in the defences (untrustworthy alarms and indicators, unworkable procedures, design and construction deficiencies, etc.) (Reason, 2000). From the following facts concluded by investigators, it was found that the victim climbed over the door switch (safety sensor/device) and entered the danger zone of the machine without activating the emergency stop (lock-out procedure). The active failure in this case is that the operator ignored/violated the inherent rule, namely not to enter a danger zone 
without activating the emergency stop. The operator acted unsafely by climbing over the safety gate. The investigators further considered the latent conditions and investigated the design of the work environment, known procedures and the build of the machine (as illustrated in pictures 1-3): (1) The safety gate (door switch) was found closed, with the victim in the danger zone; (2) The emergency stop was only activated by the first person to find the victim (Operator No.2); (3) The height of the safety gate (door switch) is $1200 \mathrm{~m}$ (refer to picture-2), while the height of the safety fence around the machine is $1800 \mathrm{~mm}$; (4) There were footprints on the frame in the upper part of the door switch (refer to picture-3); (5) Regarding the air cylinder, which is the energy supply source for the can pusher, it was found that: (a) the diameter is $100 \mathrm{~mm}$; (b) the pressure is $0.4 \mathrm{MPa}$; (c) the thrust is $3140 \mathrm{~N}(314 \mathrm{kgf})$.

Figure 3: Latent conditions

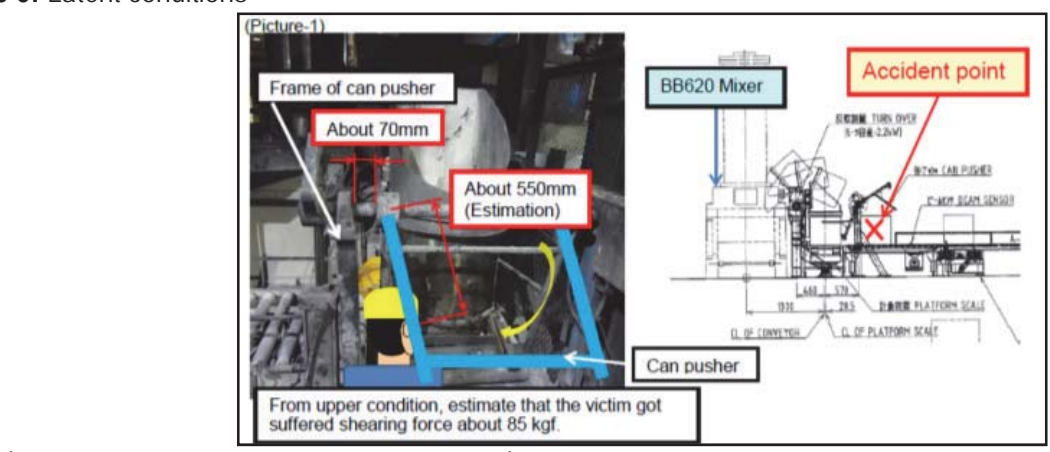

(Incident investigation report dated 18 May 2013).

Pictures 2 and 3: Latent conditions (continue)

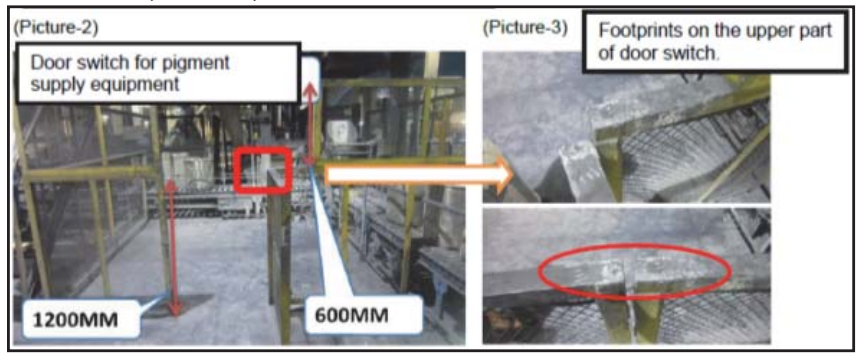

(Incident investigation report dated 18 May 2013, continue)

The error provoking conditions (the consequences that drove the unsafe behaviour) to this case is unknown, but may include time pressure, production urgency and/or fatigue. Facts that are known to the investigators (Kouji Matsuoka, General Manager, Occupational Safety, Health and Disaster Prevention Department, 2013) include: The design of the machine allowed the operator to climb over the safety gate; The operator was able to by-pass the safety sensor and to move into the danger zone without the machine switching off; The height of the safety gate is lower than the surrounding safety fence, creating access over the gate and into the danger zone; The operator failed to obey the safe operating procedure, indicating a shortfall in the system (culture, perception, attitude, leadership and management, prioritising of outcomes and goals, as discussed initially); The high pressure of the air cylinder ultimately caused the death of the operator; The air cylinder did not shut down and was able to function as normal, even though the operator was inside the danger zone. In a nutshell, the unsafe behaviour, demonstrated by the operator involved, in combination with the latent conditions of the system, created a momentary alignment of holes that permitted the course of the accident that occurred (accident trajectory). This example, based on the Swiss Cheese Model, further proof that the interactive phenomenon between man-machine-environment exist and that accidents only occur when humans interact in an unsafe way with an environment where unsafe conditions exist. Therefore, it is still argued that an accident occurs as a result of the environment demanding more of the operator than he is able to give (Oborne, 1985). Environment here refers not only to the operators' physical- or psychosocial factors alone, but rather to the organisational system and organisational behaviour as a whole. 


\subsection{Error management}

As earlier mentioned, systems management and risk management play a significant part in the occurrence of incidents and accidents. Human factor engineering (ergonomics management) considers two approaches in error management: limiting the incidence of dangerous errors and creating systems that are better able to tolerate the occurrence of errors and contain their damaging effects (Reason, 2000). The Occupational Health and Safety Act (85 of 1993) refer to the employer's responsibility to create a safe working environment, as far as reasonably practicable. As far as human error, unsafe acts or negligence is concerned, South African legislation further considers the employer's (or the reasonable person's) 'foreseeability of wrongful conduct on the part of others' (As cited in Anon, 2013). It concludes that "there are certain situations where it is foreseeable that others will commit intentional or negligent wrongs, and in such case a reasonable person must take precautions against it". 'The employer may himself therefore be negligent for failing to foresee and guard against the intentional and negligent behaviour of others' (Stansbie v Troman [1948] 2 KB 48 (CA) [1948] 1 All ER 599). Furthermore, where the employer has considered all possible alternatives and implemented as far as reasonably practicable all precautions, the employee has the obligation to interact with the environment in a safe way (OHSA, 85 of 1993, section 8). Keeping in mind that behaviour is never random, and that human error may be the result of flawed systems at work, one must also consider that the employer will be faced with certain situations where the employee is guilty of misconduct or negligent behaviour, as opposed to errors caused by consequence.

It is further very important to distinguish between human error and negligence or carelessness, which is viewed as misconduct. Negligence refers to 'failure to exercise the degree of care considered reasonable under the circumstances, resulting in an unintended injury to another party'. According to Fsp (2012) an employee who knows and understands what is expected of him and is aware of the level of care required to carry out his work tasks satisfactorily, but fails to take sufficient care, is guilty of misconduct/negligence. Although the law of delict does not distinguish different forms or degrees of negligence, or culpa (Cape Town Municipality v Payne 1923AD 207) the differences between negligence and gross negligence have been recognised in many areas of law. As Wessels, J. stated in C.S.A.R. v Adlington \& Co. 1906 TS 964 at 973, "a person is guilty of gross negligence who gives no consideration whatever to the consequences of his act". A person is guilty of ordinary negligence (culpa levis) when he, though not grossly negligent, omits to take that care that ordinary people usually take in similar circumstances...." (As cited in the High Court of South Africa, Case no. AC 30/97, cited in Davis, 2000). In Government RSA (Department of Industry) v Fibre Spinners and Weavers (Pty) Ltd 1977 (2) 324(D \& CLD) at $335 \mathrm{E}$, Didcott, J. stated that gross negligence denotes "recklessness, an entire failure to give consideration to the consequence of his actions, a total disregard of duty". In the case of S v Dhlamini 1988(2) SA 302(A) at 308 it went on to follow the dictum that gross negligence includes an attitude or state of mind characterised by 'an entire failure to give consideration to the consequences of one's actions, in other words, an attitude of reckless disregard of such consequences' (at 143 F) (As cited in the High Court of South Africa Case No. AC 30/97, by Davis, 2000).

Finally, negligence, carelessness or recklessness is viewed as a serious offence that places a great deal of strain on the organisation as a whole, whereas gross misconduct has the propensity to damage the trust relationship between the employee and the employer. In cases where negligence, as defined above, is evident, the employer may feel betrayed by the employee's actions of misconduct and disregard for rules and regulations. Where system flaws are not to blame for unsafe acts, the employer has the right to discipline unwanted behaviour. More than that, the employer is faced with the responsibility to minimise, remove or eliminate the risk, in order to provide a safe working environment for the rest of the workforce. In doing so, the employer will turn to the code of good practice (Labour Relations Act, 66 of 1995, Schedule 8) as a guide to perform a fair disciplinary procedure.

A proper investigation (planning phase) is required before the employee is charged for misconduct. The Employer must consider the "second story" (as mentioned earlier) and the full back ground of the case, prior to the incident of alleged misconduct (negligence). A neutral third party will more likely be able to determine whether the act of unsafe behaviour was due to flawed systems at work (Swiss cheese model) or due to the employee's carelessness and failure to perform according to the known and desired standard (safety culture). The employer must be clear in charging the employee for misconduct, stating the degree of negligence and the reason why it has been brought against the employee. With reference to the incident as stated in the Introduction of this article, the two employees were charged with 'negligence, in that they have failed to adhere to the safety rule not to enter into any danger zone of any moving machinery or equipment, without applying the emergency stop'. To test the substantive fairness of the charge as stated above, the employer is required to consider whether the employees were aware of the rule, or whether it can be reasonably expected of the employees to have been aware of the rule, which they duly were. Secondly, the employer has to consider whether the rule was fair or reasonable, which it rightly was. Lastly, the employer needs to consider whether the rule was broken, which in this case the rule was deliberately and knowingly broken. Taking into consideration the 
back ground prior to the incident, this act of misconduct committed by the two operators followed a previous incident where an employee was dangerously close to losing his life at the same machine. The Employer followed up on the incident by creating more awareness in terms of safe behaviour and re-introduced the number one safety rule, namely the lock-out procedure. When the two operators ignored the employer's plea to take reasonable care of their own safety and of the safety of others (OHSA, 85 of 1993, section 8), the employer viewed their behaviour as disrespectful towards the organisations safety culture and disregard for management's authority. The negligent act further stretched to recklessness, and what's more - insubordination, in that they have knowingly failed or ignored company policies and procedures.

Finally, the employer must consider a fair sanction, suitable to the degree of misconduct. As defined by case law, negligence refers to 'failure to exercise the degree of care considered reasonable under the circumstances, resulting in an unintended injury to another party', where gross negligence denotes "recklessness, an entire failure to give consideration to the consequence of his actions, a total disregard of duty". In terms of these definitions, the operators were grossly negligent and dismissal (termination of services) would be an appropriate sanction (Case number: 30/04/13; GATW6161-13). In the case study discussed in the model of 'Ajzen's Theory of Planned Behaviour', the operator showed risk-taking behaviour, which resulted in an accident. In this case it was found that the operator's behaviour was driven by a perceived subjective norm and perceived behaviour control. Does this exclude negligence? Also in the case study discussed in the 'Swiss Cheese' Model, it was found that latent conditions existed and momentary alignment of system flaws resulted in the accident. Again, does this exempt the employee for being found guilty of negligence in that he failed to comply with the safety rules? The Occupational Health and Safety Act (85 of 1993) stipulates that the employer and the employee are jointly responsible for the health and safety of the workplace, i.e., the employer has the responsibility to provide a safe work environment, as far as reasonably practicable, and in turn, the employee has the responsibility to interact with the environment in a safe way (working interface). Therefore, the employee must take responsibility for his/her actions and must be held accountable for negligent or risk-taking behaviour.

With regard to behaviour based safety, it is important to understand that behaviour is never random and inspired by a desirable outcome. To understand this, the employer has the advantage to be able to predict and foresee unwanted behaviour. Behaviour based safety allows the employer to perform hazard identification and risk assessment to promote safe behaviour, safe operating procedures and to ensure compliance with rules and regulations. Psychosocial risk management is important for sound human resource management and supports labour relations management in that it relies on reinforcements, rather than punishment. By performing a proper risk assessment, analysing the physical and psychosocial environment allows the employer to foresee wrongful conduct on the part of others (negligence), and to change the predicted behaviour. Therefore, it is can be that the psychosocial risk environment has an adverse effect on labour relations management.

\section{Research Methodology}

\subsection{Sample}

For the purpose of this quantitative research study, a structured questionnaire was used to collect the data. This section describes the sampling method, research participants and study population, questionnaire and statistical analysis conducted.

\subsection{Study population and research participants}

The research was conducted at one of South Africa's largest factories in the manufacturing industry. The research participants consist of adult employees employed by this specific manufacturing company in different departments and at different levels. This industry is deemed appropriate due to the nature of business found in the manufacturing industry where it is expected that occupational risks, as well as health and safety hazards will be present to some degree. Simple random samples of 280 employees employed on a full-time basis, including senior management, middle/line management, office staff and operator level, responded to the questionnaire. However, after receiving the questionnaire, only 251 answer sheets were accepted by the researcher. The questionnaire was issued with a cover letter and included with the participants' payslips. The questionnaire was promoted as voluntary and anonymous. Permission was obtained to conduct the study at the factory. The purpose of the study was explained verbally and in writing to management and to the workers. The participants have been assured that no negative consequences will emerge for those who participated in the research process. The final report will be made available to both management and the workers. 
Simple random samples (251) were obtained from employees working at the factory, out of a total of 816 employees employed at the same manufacturing company. The organisational design consists out of: Senior Executive Management - 12; Top / Departmental Management - 24; Line management (Foremen) - 57; Office Staff - 62; Artisans -56; Operators -603 . In order to determine the study population the following formula has been used $(N=814 ; n=200)$ :

$\frac{\mathrm{n} 1}{\mathrm{n}}=\mathrm{N} 1$.

Table 3: Demographic characteristics of respondents

\begin{tabular}{|l|c|c|c|}
\hline Stratum & Stratum extent & Sample & Participants \\
\hline Senior / Executive management & 12 (N1) & 3 & - \\
\hline Top / Departmental management & 24 (N2) & 6 & 13 \\
\hline First line management (foremen) & 57 (N3) & 14 & 14 \\
\hline Office Staff & 62 (N4) & 15 & 38 \\
\hline Artisans & 56 (N5) & 14 & 51 \\
\hline Operators, Forklift- / Crane operator, other floor workers. & 603 (N6) & 148 & 135 \\
\cline { 2 - 4 } & Total & 200 & 251 \\
\hline
\end{tabular}

Figure 4:

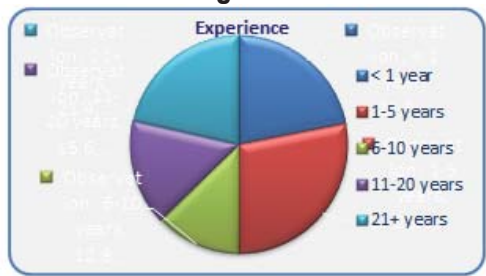

Figure 5:

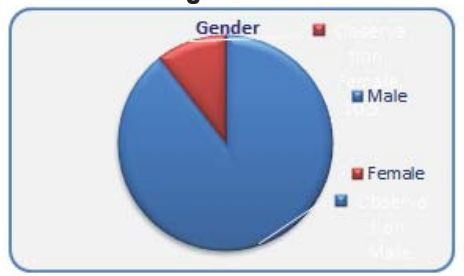

\subsection{Measuring Instrument}

A majority of respondents were male (89.5\%), while female respondents represented $10.5 \%$ (Figure 2). This is consistent with the fact that the majority of employees employed at the factory are male employees. Furthermore, the largest group of the respondents (28\%) have experience at the manufacturing company for period of approximately $1-5$ years, followed by a group of respondent who have been employed for more than 21 years (21.4\%) and less than one year $(21.8 \%)$, while the minority of respondents have been employed for the periods between $6-10$ years $(12.8 \%)$ and between $11-20$ years $(15.6 \%)$.

\subsection{The research questionnaire}

The questionnaire was drafted from the Dutch Musculoskeletal Questionnaire (TNO Work and Employment, 2001), Ergonomics Risk Identification and Assessment Tool, (CAPP and CPPI Ergonomics Working Group, 2000), HSE Safety Climate Survey Tool (Health and Safety Executive, 2002), Survey Ergonomics in the Workplace (National Seafood Sector Council, 2005). The questionnaire was divided into subsections addressing 1) health, including physical fitness, strength and endurance; 2) work, including type of work, rotation, repetitiveness and workload; 3) employee wellness, including job satisfaction, exhaustion and work-home balance; 4) organisational culture, including management commitment, expectations, perceptions and organisational climate; and 5) labour relations, including the employment relationship between employer and employee and behaviour. The validity of the questionnaire was tested in order to ensure a suitable and appropriate measuring battery to answer the specific research questions.

\section{Statistical Analysis}

The statistical analysis of the data was conducted through the assistance of different statistical techniques, carried out by the SPSS program (SPSS Inc, 2007). The analysis was done in three stages: a factor analysis, a cluster analysis and an analysis of significant differences between two group clusters of employees working at the manufacturing plant. Firstly, a principal axis factor analysis, using an Oblimin rotation with Kaiser normalisation, was performed to explain the variancecovariance structure of a set of variables through a few linear combinations of these variables. The Kaiser-Meyer-Olkin measure of sampling adequacy was used to determine whether the covariance matrix was suitable for factor analysis. 
Kaiser's criteria for the extraction of all factors with eigenvalues larger than one were used because they were considered to explain a significant amount of variation in the data. All items with a factor loading greater than 0.3 were considered as contributing to a factor, and all items with loadings less than 0.3 as not significantly correlated with this factor (Steyn, 2000). Any item that cross loaded onto two factors with factor loadings both greater than 0.3 was categorised in the factor where interpretability was best. A reliability coefficient (Cronbach's alpha) was computed for each factor to estimate its internal consistency. All factors with a reliability coefficient above 0.6 were considered as acceptable in this study. The average inter-item correlations were also computed as another measure of reliability, and lie between 0.15 and 0.55 (Clark \& Watson, 1995).

Secondly, a cluster analysis, using Ward's method with Euclidean distances, was performed. A cluster analysis is a multivariate interdependence technique, with the primary objective of classifying objects into relatively homogeneous groups based on the set of variables considered, and it is mostly an exploratory technique (Hair, Bush \& Ortinau, 2000). Hierarchical clustering makes no assumptions concerning the number of groups or group structure. Instead, the members are grouped together based on their natural similarity (Johnson \& Wichern, 2007). This research did not take an a priori view of which data points should fall into which segment. Rather, a hierarchical cluster analysis was used to explore the natural structure of the data, by means of Ward's method of Euclidean distances. Thirdly, independent t-tests, two-test frequency tables, and chi-square tests were used to investigate any significant differences between the clusters. The $p$ value was analysed to consider the statistical significance of the results. A small $p$-value $(<0.5)$ is considered as sufficient evidence that the result is statistically significant (Ellis, 2003). In many cases, it is important to know whether a relationship between two variables is particularly significant. The statistically significance of such a relationship is determined with the Chi-square test, to conclude the effect of size: (a) Small effect: $w=0.1$, (b) medium effect: $w=0.3$, large effect: $w=0.5$. A relationship with $w \geq 0.5$ is considered as particularly significant (Ellis \& Steyn, 2003).

\section{Results and Discussion}

This section discusses the results of the factor analysis and presents the results of the t-tests and cross-tabulations with chi-square tests to investigate significant differences. The two clusters represent the lower-skilled respondents, including operators, forklift-/crane operators, artisans, and other floor workers (cluster 1) in relation to higher-skilled respondents, including support staff, line-, middle-, and top management (cluster 2). Cluster 1 further represents the majority of employees working at the manufacturing plant, while cluster 2 represent the smaller group of people employed at the manufacturing plant. The respondents from Cluster 1 are more exposed to the physical work environment and interaction between the man-machine environment and more likely to perform physical- and tiring tasks.

Table 4: T-test result for employee physical-/mental health and work input factors in two clusters.

\begin{tabular}{|ll|c|c|c|c|c|c|c|}
\hline & & $\mathrm{N}$ & Mean & Std. Deviation & Std. Error Mean & Effect size (w) & $\mathrm{t}$-value & $\mathrm{P}$ \\
\hline \multirow{2}{*}{ Health Status } & Cluster 1 & 161 & 3.609 & .6242 & .0492 & 0.09 & .624 & .534 \\
& Cluster 2 & 65 & 3.554 & .5871 & .0728 & & & \\
Fitness Status & Cluster 1 & 152 & 3.257 & .8178 & .0663 & 0.21 & 1.416 & .159 \\
& Cluster 2 & 65 & 3.077 & .8716 & .1081 & & & \\
Work requires strength & Cluster 1 & 159 & 3.277 & .6927 & .0549 & 0.78 & 5.628 & .000 \\
& Cluster 2 & 65 & 2.600 & .8624 & .1070 & & & \\
Work requires endurance & Cluster 1 & 141 & 3.199 & .6784 & .0571 & 0.34 & 2.342 & .021 \\
& Cluster 2 & 61 & 2.918 & .8225 & .1053 & & & \\
Health complaints & Cluster 1 & 157 & 1.764 & .8559 & .0683 & 0.10 & .817 & .415 \\
& Cluster 2 & 65 & 1.677 & .6640 & .0824 & & & \\
Suffering from tension at work & Cluster 1 & 155 & 2.335 & 1.0768 & .0865 & 0.37 & -2.949 & .004 \\
& Cluster 2 & 65 & 2.738 & .8529 & .1058 & & & \\
Feeling nervous at work / anxiety & Cluster 1 & 153 & 2.000 & 1.0942 & .0885 & 0.06 & .437 & .662 \\
& Cluster 2 & 65 & 1.938 & .8817 & .1094 & & & \\
Feeling tired in the mornings & Cluster 1 & 156 & 2.269 & 1.0370 & .0830 & 0.06 & -.476 & .635 \\
Feeling physically tired at the & Cluster 2 & 63 & 2.333 & .8424 & .1061 & & \\
end of a working day & Cluster 1 & 159 & 3.119 & .8669 & .0687 & 0.32 & 2.270 & .025 \\
Feeling mentally tired at the end & Cluster 2 & 64 & 2.844 & .8012 & .1001 & & & \\
of a working day & Cluster 1 & 157 & 2.720 & 1.0429 & .0832 & 0.31 & -2.453 & .015 \\
\hline
\end{tabular}


As Table 4 shows, lower skilled workers and higher-skilled workers differ significantly based on their experience of physical- and mental work input and health status $(w \geq 0.3)$. In general, employees feel that their health status is good. Employees who are more exposed to the physical environment of the manufacturing industry (cluster 1 ), have a better perception of their own fitness status, in that their work requires more physical strength, while higher-skilled employees from cluster 2 feel that their work requires more endurance (patience or persistence). In correlation with this statement, it is shown that higher skilled workers experience more frustration and tension at work, while the level of work anxiety is experienced relatively the same between both groups. Lower-skilled workers are physically more tired at the end of a working day, while higher skilled workers are more mentally tired at the end of a working day.

Table 5: T-test result for employee wellness - home/work balance factors in two clusters.

Group Statistics

\begin{tabular}{|ll|c|c|c|c|c|c|c|}
\hline \multicolumn{1}{|c|}{ Skill } & & $\mathrm{N}$ & Mean & Std. Deviation & Std. Error Mean & Effect size (w) & t-value & $\mathrm{P}$ \\
\hline Experience of psychosocial & Cluster 1 & 156 & 2.3553 & .63774 & .05106 & 0.29 & 2.172 & .032 \\
stress & Cluster 2 & 64 & 2.1682 & .55490 & .06936 & & & \\
Experience of job satisfaction & Cluster 1 & 155 & 2.8817 & .60339 & .04847 & 0.37 & -2.900 & .004 \\
& Cluster 2 & 64 & 3.1042 & .47559 & .05945 & & & \\
\multirow{2}{*}{ Experience of workload } & Cluster 1 & 156 & 2.4295 & .52365 & .04193 & 0.67 & 4.921 & .000 \\
& Cluster 2 & 64 & 2.0807 & .45715 & .05714 & & & \\
\hline
\end{tabular}

In relation with Table 4, Table 5 further shows that lower-skilled workers and higher-skilled workers differ significantly based on their experience of psychosocial stress, job satisfaction and experience of workload ( $w \geq 0.3$ ). In this section however it was found that workers who are more exposed to the physical environment of the manufacturing industry, suffer on average more with psychosocial stress, perceive less job satisfaction and experience a higher rate of workload.

Table 6: T-test result for organisational culture/-climate at the manufacturing plant in two clusters.

Group Statistics

\begin{tabular}{|ll|c|c|c|c|c|c|c|}
\hline \multicolumn{1}{|c|}{ Skill } & & $\mathrm{N}$ & Mean & Std. Deviation & Std. Error Mean & Effect size (w) & t-value & $\mathrm{P}$ \\
\hline Experience of social support. & Cluster 1 & 156 & 2.6092 & .66496 & .05324 & 0.27 & -2.264 & .025 \\
& Cluster 2 & 64 & 2.7891 & .47175 & .05897 & & & \\
General perception of the employer. & Cluster 1 & 156 & 2.7217 & .73902 & .05917 & 0.21 & -1.725 & .087 \\
& Cluster 2 & 64 & 2.8766 & .54039 & .06755 & & & \\
General perception of safety at work. & Cluster 1 & 153 & 3.072 & 1.0007 & .0809 & 0.19 & -1.609 & .109 \\
General perception of tolerance for & Cluster 2 & 62 & 3.258 & .6512 & .0827 & & & \\
safety violations. & Cluster 1 & 153 & 1.895 & 1.1480 & .0928 & 0.19 & 1.367 & .174 \\
General perception of Management's & Cluster 2 & 62 & 1.677 & 1.0207 & .1296 & & & \\
safety imager 1 & 151 & 3.099 & .9644 & .0785 & 0.20 & -1.597 & .112 \\
\hline
\end{tabular}

Table 6 shows a small to medium effect $(w<0.3)$ or difference between lower- and higher-skilled workers, indicating that the general perception of the organisational safety culture is perceived relatively as the same between the two groups. The importance of safety at work is viewed as a high priority at all levels of the organisation. However, cluster 2 (higher skilled workers) experiences a higher level of social support, has a more positive view of the employer and has a better perception of management's safety image. These differing perceptions between the two groups relating to the organisation's safety culture, image and climate may form a basis of differing expectations and needs, subsequently influencing the labour relationship between employer and employee. Table 7 below shows the effect of these differing views and expectations on the labour relationship and favourable behaviour. In support of literature, all levels and people from different backgrounds and perceptions experience the same safety culture, where a safety culture exists in a given organisation. 
Table 7: T-test result for labour relations perceptions and favourable behaviour at the manufacturing plant in two clusters.

Group Statistics

\begin{tabular}{|c|c|c|c|c|c|c|c|c|}
\hline \multicolumn{2}{|l|}{ Skill } & $\mathrm{N}$ & Mean & Std. Deviation & Std. Error Mean & Effect size & t-value & $P$ \\
\hline $\begin{array}{l}\text { General perception of } \\
\text { accident causes. }\end{array}$ & $\begin{array}{l}\text { Cluster } 1 \\
\text { Cluster } 2\end{array}$ & $\begin{array}{c}153 \\
64\end{array}$ & $\begin{array}{l}3.0268 \\
3.3625\end{array}$ & $\begin{array}{l}.69368 \\
.55649\end{array}$ & $\begin{array}{l}.05608 \\
.06956\end{array}$ & 0.48 & -3.757 & .000 \\
\hline Attitude towards unsafe & Cluster 1 & 154 & 1.6380 & .52023 & .04192 & 0.10 & -.667 & .506 \\
\hline behaviour. & Cluster 2 & 64 & 1.6927 & .56380 & 07048 & & & \\
\hline General perception of & Cluster 1 & 154 & 3.3598 & 49897 & 04021 & 0.27 & -1.832 & .070 \\
\hline responsibility and discipline. & Cluster 2 & 64 & 3.4974 & .50722 & .06340 & & & \\
\hline General feeling towards a high & Cluster 1 & 150 & 2.847 & .9177 & .0749 & 0.34 & 2.492 & .014 \\
\hline risk work environment. & Cluster 2 & 64 & 2.531 & .8159 & 1020 & & & \\
\hline General perception of & Cluster 1 & 146 & 2.363 & 1.0627 & . 0880 & 0.36 & 2.540 & 012 \\
\hline Management's responsibility. & Cluster 2 & 62 & 1.984 & .9494 & 1206 & & & \\
\hline General perception of the & Cluster 1 & 142 & 2.155 & .7746 & .0650 & 0.50 & 3.705 & .000 \\
\hline $\begin{array}{l}\text { Employer's influence towards } \\
\text { accidents. }\end{array}$ & Cluster 2 & 64 & 1.766 & .6605 & 0826 & & & \\
\hline Perception of the Employer- & Cluster 1 & 147 & 2.367 & .8996 & .0742 & 0.21 & 1.455 & 148 \\
\hline Employee Safety Relations & Cluster 2 & 63 & 2.175 & .8714 & 1098 & & & \\
\hline
\end{tabular}

As Table 7 shows, lower-skilled workers and higher-skilled workers differ significantly based on their perception of the employer's responsibility in terms of safety and their experience or views about causes of accident in the organisation ( $w$ $\geq 0.3 ; w \geq 0.5$ ). Cluster 2 (higher-skilled workers) more significantly agreed that accidents in the workplace occur as a result of unsafe behaviour, unsafe interaction with the environment and failure to obey safety rules, in relation with the response from cluster 1 (lower-skilled workers). Both groups however strongly agreed that safety rules may never be compromised or broken. This perception supports the finding in Table 6 above that the safety culture is perceived relatively the same between the two groups. Nevertheless, cluster 2 (higher skilled workers) felt stronger that it is fair to discipline unsafe behaviour or violations of safety rules. Cluster 1 (lower skilled workers) experience more anxiety in a high risk work environment and is more likely to believe that the employer is responsible for their safety.

It may be concluded that workers, who are exposed to a higher risk work environment experience a greater fear in terms of safety in their areas of work based on their physical interaction with the environment. These workers are more likely to believe that accidents are the result of an unsafe workplace or work environment opposed to unsafe behaviour. Furthermore, this group of workers are more likely to expect the employer to foresee safety risks and hazards (as stated initially) and holds the employer responsible for their safety at work; whereas the higher-skilled workers (junior-, line-, middle- and top management) expect the workers to interact with the environment in a safe way and are more likely to believe that most accidents occur from unsafe behaviour, poor performance or misconduct and a failure to adhere to safety rules.

\section{Conclusion}

In conclusion, the article explored occupational risk and the dynamics of unsafe acts, unwanted behaviour and misconduct. The assumption was made that the psychosocial risk environment could influence employee behaviour and subsequently the labour relationship between employer and employee. The unique nature and commonness of negative acts, such as unsafe behaviour, human errors, poor performance and negligence, also referred to as unsafe practice, were explored in correlation with system flaws, safety culture, leadership, perceptions, expectations and organisational behaviour as a whole. Case studies were used as examples to answer and explore the question why incidents and accidents in the workplace occur within the working interface dynamic. The literature review investigated the nature of psychosocial risks and the origin of negative acts or unsafe behaviour. It has been found that behaviour is not random and does not occur without some thought process preceding it. Furthermore, it was established that accidents do not always follow automatically from risk-taking behaviour. Within the working interface dynamic, the key components include: the human; the machine and the method of interaction between the components. When the method is flawed, for various reasons, it can create terrible consequences for individuals and the organisation as a whole. It is also observed that the overall dynamics of the organisation's activities, systems, and organisational behaviour play a significant role in safe operational efficiency. Furthermore, in correlation with this statement, the impact of (safety) culture was viewed in particular and to the highest degree as an important component, because it is how people perceive, understand and commit to safety at work, which can be measured by observing the vision, values and commitment of people at all levels. 
Attitudes are a key element of a safety culture, as such, attitudes and behaviour are much more capable of predicting employees' safety performance at work. The findings of the statistics drawn from the research questionnaire also portray comparisons between unsafe behaviour and psychosocial risk factors, in that employees who interact more directly with the physical work environment of the manufacturing plant perceive their work to be physically tiring and that it requires more physical strength, while higher-skilled employees feel that their work requires more endurance, patience or persistence. In correlation with this statement, it is shown that higher-skilled workers experience more frustration at work, and experience more tension as a result of higher expectations and based on the levels of job responsibility. Despite these differing expectations and level of responsibilities and exposure, the intensity of work anxiety is experienced relatively the same between both groups (lower- and higher-skilled worker). Therefore it can be said that occupational stress is a relative term, independent or free from the level of work or responsibility and physical or mental outputs of employees. Lower-skilled workers are physically more tired at the end of a working day, while higher-skilled workers are more mentally tired at the end of a working day, but the level of work stress/anxiety was psychologically experienced to the same degree at both levels. It is important here to understand that the term 'psychological' is different from 'psychosocial', and refers more narrowly to thought processes and behaviour of individuals. Psychosocial risks are organisational factors that affect the psychological safety and health of employees. Psychosocial factors include the way the work is carried out (deadlines, workload, work methods) and the context within which work occurs, including relationships and interactions with managers and supervisors, colleagues and co-workers and clients or customers.

Within this context, it was found that workers, who interact more directly with the physical environment of the manufacturing industry, suffer on average more with psychosocial stress, perceive less job satisfaction and experience a higher rate of workload because certain jobs are more demanding than others and certain features will generate high levels of psychosocial pressure, including unpleasant and dangerous physical conditions; monitoring of devices or materials; as well as repeated exchange of information with others. These are typical examples of activities that the lower skilled workers will perform on a normal day-to-day basis at the manufacturing plant. Factors such as little control over the work environment; lack of participation in decision-making; sudden reorganisations and unexpected changes in work schedules and not enough time to do the expected duties was also included as the dynamic differences between superiors and subordinates. Furthermore, higher-skilled workers experienced a higher level of social support, have a better impression of the employer, and have a better and more positive perception of management's safety image. These differing perceptions between the two groups relating to the organisation's safety image and climate may form a basis of differing expectations and needs, subsequently influencing the labour relationship between employer and employee. Furthermore, the higher-skilled workers felt stronger in terms of disciplining unsafe behaviour or violations of safety rules, while lower-skilled workers believe that the employer is responsible for their safety. Furthermore, higher-skilled workers feel that accidents in the workplace occur as a result of unsafe behaviour, unsafe interaction with the environment and failure to obey safety rules, as opposed to the response from lower-skilled workers. Therefore, it can be concluded that the psychosocial risk environment, will either provoke desirable or undesirable behavior, from the individual employee, subsequently influencing the trust relationship between employer and employee and the organisation as a whole.

\section{References}

Ajzen I.1991. The theory of planned behaviour. Organisational behaviour and human decision processes, 50, p. 188.

Anon 2013. The negligence of others. [Online] Available: http://www.google.co.za/url?sa=t\&rct=j\&q=negligent\%20 behaviour\&source= web\&cd=10\&cad=rja\&ved=0CFwQFjAJ\&url=http\%3A\%2F\%2Fwww.hoststudio.co.za\%2Falina\%2Fdel2011\%2FDelict\%2520Negli gence\%2520of\%25200thers\%2520onwards.students.doc\&ei=nCzUUfjeNoj_4QT8n4CQBQ\&usg=AFQjCNHwV3G3lkdXbyl21oke L7ICEgfpfQ\&bvm=bv.48705608,d.ZWU

Attock Refinery Limited 2013. Behavioural safety at workplace. Triple Bottom Line Magazine [Online] Available: http://www.tbl.com. pk/behavioural-safety-at-workplace/

Bailey R W 1982. Human performance engineering. Englewwood Cliffs, New York: Pretice Hall Inc.

Bowin R B, Harvey D 2001. Human Resource Management: An Experiential Approach. Englewood Cliffs, NJ: Prentice Hall.

Bridger R S 2003. Introduction to ergonomics. New York: Taylor \& Francis Group.

Bruton A K, Kendall N A S, Birrell L N, Bainbridge L C 2008. Management of upper limb disorders and the Biopsychosocial Model (RR 596) Health \& Safety Executive.

Canadian Centre of Occupational Health \& Safety 2012. Musculoskeletal Disorders - Psychosocial Factors. As cited by http://www.ccohs.ca/oshanswers/psychosocial/stress.html

Cassitto M G, Fattorini E, Gilioli R, Rengo C 2013. Protecting Workers Health Series No. 4 Raising awareness to psychological harassment at work. As cited by World Health Organisation http://www.who.int/occupational_health/publications /harrassment/en/index.html

Clark L A, Watson D 1995. Constructing validity: basic issues in objective scale development. Psychological Assessment, 7(3), 309-319. 
Clarke S, Robertson I T 2005. A metaanalytic review of the Big Five personality factors and accident involvement in occupational and non-occupational settings. Journal of Occupational and Organizational Psychology, 78, 355-376.

Daniels A C 2000. Bringing out the best in people: How to apply the astonishing power of positive reinforcement (2nd ed.). New York: Mc Graw-Hill.

Ellis S M, Steyn H S 2003. Practical significance (effect size) versus or in combination with statistical significance ( $p$-values). Management Dynamics, 12(4), 51-53.

Flemming M, Lardner R 2002. Strategies to promote safe behaviour as part of health and safety management system. HSE: Norwich.

Fsp 2012. Why negligence is misconduct, not incapacity. As cited by http://labourandhrclub.fspbusiness.co.za/articles/dismissals/whynegligence-is-misconduct-not-incapacity-4.html

Geller E S 2005. Behavior-Based Safety and Occupational Risk Management. Behavior Modification 29(3), 539-561.

Germai G L, Bird D J, Labuschagne C J 2011. Safety, Health, Environmental and Quality: guide to managing risk. Randburg: International Risk Control America, LLC and IRCA Global.

Gilbert M 2010. Guarding Minds at work: A guide to workplace psychological safety and health. Cited by www.pnwerarchive.org/LinkClick.aspx?fileticket...tabid=1892\&mid...

Grandjean E 1988. Fitting the task to the man: a textbook occupational ergonomics (4th ed.). London: Taylor \& Francis

Green N, Taylor K 2008. Psychosocial risk factors: what are they and what are they important? Wellnomics Ltd., Ref 04/12/2008 v1: New Zeeland.

Hair J F, Bush R P, Ortinau D J 2000. Marketing research: a practical approach to the new millennium. Boston: Irwin/McGraw-Hill

Hale A R 2000. Culture 's confusions. Safety Science, 34: 1-14.

Health and Safety Authority 2004. Improving safety behaviour at work: Guidance for employers, managers and the self-employed. http://www.hsa.ie/eng/Publications_and_Forms/Publications/Safety_and_Health_Management/Improving_Safety_Behaviour_at_ Work.pdf

Hopkins A 2002. Safety Culture, Mindfulness and Safe Behaviour: Converging ideas? The Australian National University, Working Paper 7. As cited by National Research Centre for OHS Regulations.

Houtman I L D 2008. Monitoring psychosocial risks at work. Prima-ef Consortium, 08 PRIMA-EF ISN 978-88-6230-040-7.

Johnson R A, Wichern D W 2007. Applied multivariate statistical analysis. Pearson Prentice Hall.

Keltz T 1994. Learning from accidents. Oxford: Gulf.

Kreitner, R., \& Kinicki, A. (2008). Organizational behaviour (8th ed.). New York: McGraw-Hill.

Kruger A, Van Wyngaard P 2009. Becoming peak performers. Occupational Risk Management 5(6), 8-9.

Kruger A, Van Wyngaard P 2009. Unsafe context and logic lead to unsafe acts. Occupational Risk Management 5(3), 22-23.

Leka S, Cox T 2008. The European framework of psychosocial risk management. PRIMA-EF. I-WHO Publications: Nottingham.

Leka S, Griffiths A, Cox T 2005. Work organisation and stress: systematic problem approaches for employers, managers, and trade union representatives. WHO Publications: France.

Leka S, Griffiths A, Cox T 2013. Protecting Workers' Health Series No. 3 Work organisation and stress. As cited by World Health Organisation http://www.who.int/occupational_health/publications/stress/en/index.html

Meyerson D, Martin J 1987. Curtural change: an integration of three different views. Journal of Management Studies, 24:623-47.

Newell S 2002. Creating the healthy organisation: well-being, diversity \& ethics at work. London: Thomson.

Oborne, D. J. (1985). Ergonomics at work. Chichester: John Wiley \& Son.

Psych Press 2009 - Talent Management Psychologists. Assessing Work Safety Behaviour: A New Direction. [Online] Available: http://psychpress.com.au/psychometric/files/Assessing_Work_safety.pdf?\&topic=220

Reason J 1997. Human error. Cambridge University Press: New York.

Reason J 2000. Human error: models and management. British Medical Journal, 320(7237), p. 768-770.

Reiman T, Oedewald P 2002. The assessment of organisational culture: A methodological study. ESPOO 2002 VTT RESEARCH NOTES 2140

Rick J, Briner R B, Daniels K, Perryman S, Guppy A 2001. A critical review of psychosocial hazard measures, Contract Research Report, 356/2001, HSE: Norwich, UK, as cited by Green, N., \& Taylor, K. (2008).

Ritchie S, Martin P 1999. Motivation management. Hampshire: Gower Publishing limited.

Robbins S P, Odendaal A, Roodt G 2007. Organisational behaviour: Global and Southern African perspectives. Pearson Education South Africa: Cape Town.

Samra J, Gilbert M, Shain M, Bilsker D 2012. Psychosocial Factors. Centre for Applied Research in Mental Health and Addiction. As cited by www.guardingmindsatwork.ca/info/resources

Schein E 1985. Organizational culture and leadership. San Francisco: Jossey-Bass.

Steyn H S 2000. Practical significance in the difference in means. South African Journal of Industrial Psychology, 26(3), 1-3

Strydom L 2009. Government and industry should focus on work interface behaviour. Occupational Risk Management 5(3), 18-19. 